\title{
Low Vitamin D Levels are Associated with Vascular Endothelial Dysfunction in Patients with Type 2 Diabetes: A Retrospective Study
}

\section{Kenichi Tanaka}

University of Occupational and Environmental Health, Japan https://orcid.org/0000-0003-3538-3163

\section{Yosuke Okada}

University of Occupational and Environmental Health Japan

Maiko Hajime

University of Occupational and Environmental Health Japan

Yoshiya Tanaka ( $\sim$ tanaka@med.uoeh-u.ac.jp )

\section{Research}

Keywords: 25-hydroxyvitamin D, reactive hyperemia index, type 2 diabetes, vascular endothelial function

Posted Date: June 18th, 2020

DOI: https://doi.org/10.21203/rs.3.rs-35511/v1

License: (c) (i) This work is licensed under a Creative Commons Attribution 4.0 International License.

Read Full License 


\section{Abstract}

Background: The aim of this study was to determine the association between serum 25-hydroxyvitamin D $(25(\mathrm{OH}) \mathrm{D})$ levels and vascular endothelial function in patients with type 2 diabetes (T2D).

Methods: This retrospective study included 113 T2D patients who were admitted for in-hospital diabetes educational program and underwent measurements of serum 25(OH)D levels and reactive hyperemia index $(\mathrm{RHI})$. The primary endpoint was the association between serum 25(OH)D levels and $\mathrm{RHI}$ in T2D patients.

Results: Serum 25(OH)D levels correlated significantly with RHI in T2D patients $(r=0.285, p=0.002)$. Receiver operating characteristic (ROC) curve analysis showed that serum 25(OH)D level of $16.5 \mathrm{ng} / \mathrm{mL}$ is the optimal cut-off level for predicting vascular endothelial dysfunction $(\mathrm{RHI}<1.67)$, with a sensitivity of $68.5 \%$, specificity of $67.9 \%$, and area under the ROC curve (AUC) of 0.668 (95\% confidence interval [CI]: $0.566-0.770, p=0.002)$. The mean RHI was significantly lower $(1.70 \pm 0.54)$ in patients with low $25(\mathrm{OH}) \mathrm{D}$ levels $(n=56,25(\mathrm{OH})$ D levels $<16.5 \mathrm{ng} / \mathrm{mL})$ than that $(1.99 \pm 0.58$ vs.; $p<0.001)$ of patients with high $25(\mathrm{OH})$ D levels $(\mathrm{n}=57,25(\mathrm{OH}) \mathrm{D}$ level $>16.5 \mathrm{ng} / \mathrm{mL})$. The proportion of patients with $\mathrm{RH}<1.67$ was also higher in the low $25(\mathrm{OH}) \mathrm{D}$ group than in the high $25(\mathrm{OH}) \mathrm{D}$ group ( $38 \%$ vs. $18 \%$; $\mathrm{p}<0.001)$. Multivariate logistic regression analysis identified serum $25(\mathrm{OH}) \mathrm{D}$ levels $<16.5 \mathrm{ng} / \mathrm{mL}$ was associated with increased odds of $\mathrm{RHI}<1.67$ (odds ratio $4.598,95 \% \mathrm{Cl} 1.961-10.783, \mathrm{p}<0.001$ ).

Conclusions: The results demonstrated the association of serum $25(\mathrm{OH}) \mathrm{D}$ levels with endothelial function in T2D patients and identified serum 25(OH)D level of $<16.5 \mathrm{ng} / \mathrm{mL}$ as a predictor of vascular endothelial dysfunction. Serum $25(\mathrm{OH}) \mathrm{D}$ level is a potentially useful marker of vascular endothelial dysfunction in T2D patients.

\section{Background}

Patients with type 2 diabetes (T2D) are at high risk of macroangiopathy compared to non-diabetics, with approximately 2-6-times higher risks of myocardial infarction and death related to ischemic heart disease and 2-3-times higher risk of cerebral infarction [1-3]. Such high cardiovascular risk cannot be fully explained by traditional risk factors only, such as age, sex, hypertension, dyslipidemia, and smoking, but it seems to be associated also with endothelial dysfunction, microalbuminuria, and inflammation [4]. Evidence shows that vascular endothelial dysfunction occurs at an early stage of arteriosclerosis [5] and that in T2D, vascular endothelial dysfunction can be observed during early glucose intolerance [6]. It is therefore important to assess endothelial function for the early detection of arteriosclerosis.

Vitamin $\mathrm{D}$ plays an important role in calcium homeostasis and bone metabolism through the regulation of calcium absorption from the intestine, and its deficiency has been linked to all-cause mortality, cardiovascular mortality, and heart failure [7, 8]. T2D patients have lower serum 25-hydroxyvitamin D $(25(\mathrm{OH}) \mathrm{D})$ levels than non-diabetics $[9,10]$. T2D patients with vitamin D deficiency also have limited brachial flow-mediated dilation (FMD) [11]. FMD measurement has been used traditionally for the 
assessment of vascular endothelial function. Recently, a new device (EndoPAT 2000, Itamar Medical, Caesarea, Israel) using peripheral arterial tonometry (PAT), with established objectivity and reproducibility, has been increasingly employed a noninvasive method for the assessment of vascular endothelial function [12]. Moreover, the usefulness of reactive hyperemia index (RHI) in predicting vascular diseases has been reported previously [13]. However, clinical studies using RHI in T2D patients are limited compared to those using FMD, and only a few studies have investigated the association between vitamin D status and RHI in T2D patients. The aim of this study was to determine the association between serum vitamin $\mathrm{D}$ levels and vascular endothelial function as assessed by RHI in T2D patients.

\section{Methods}

\section{Patients}

Of the patients with T2D aged over 20 years who were admitted to the Hospital of the University of Occupational and Environmental Health, Japan, for in-hospital diabetes educational program between April 2014 and December 2018, the present study analyzed those who underwent measurements for serum $25(\mathrm{OH}) \mathrm{D}$ levels and reactive hyperemia index $(\mathrm{RHI})$. The following patients were excluded: those with type 1 diabetes mellitus, severe infection or serious trauma, renal dysfunction (estimated glomerular filtration rate [eGFR] of $<30 \mathrm{~mL} / \mathrm{min} / 1.73 \mathrm{~m}^{2}$ ), being treated at that time for osteoporosis, using calcium and/or vitamin D supplements, and those found to have abnormal hormone profile (excluding those with hormone levels maintained within the normal range by treatment).

Diabetic complications were evaluated in the present study as follows: diabetic retinopathy was diagnosed based on the results of funduscopic examination performed by expert ophthalmologists and classified according to the Davis classification, into no diabetic retinopathy; simple retinopathy; preproliferative retinopathy; and proliferative retinopathy. Diabetic nephropathy was considered positive in patients with urinary albumin excretion rate (presented as urinary albumin-to-creatinine ratio [UACR]) of $\geq 30 \mathrm{mg} / \mathrm{g}$ creatinine and/or an eGFR of $<30 \mathrm{~mL} / 1.73 \mathrm{~m}^{2}$, in accordance with the Classification of Diabetic Nephropathy 2014 in Japan [14]. Diabetic neuropathy was diagnosed by the presence of two or more clinical symptoms (bilateral spontaneous pain, hypoesthesia, or paresthesia of the legs), absence of Achilles tendon reflexes, and decreased vibration sensations in response to a $\mathrm{C} 128$ tuning fork. Patients who had already been diagnosed with coronary heart disease, cerebrovascular disease, or arteriosclerosis obliterans were considered to have macrovascular complications at the time of enrollment.

The study protocol was approved by the ethics committee of the University of Occupational and Environmental Health, Japan (Approval No. H27-186) and informed consent was obtained from all participants.

\section{Study design}


This was a retrospective study. At admission, we collected patient data including age, sex, blood pressure, body mass index (BMI), duration of diabetes, presence of diabetic microangiopathy or macroangiopathy, presence of hypertension, presence of dyslipidemia, antidiabetic drug use, antihypertensive drug use, and antilipidemic drug use. The levels of fasting plasma glucose, $\mathrm{HbA} 1 \mathrm{c}$, fasting plasma insulin (FPI), serum C peptide (CPR), low-density lipoprotein cholesterol (LDL-C), high-density lipoprotein cholesterol (HDL-C), and triglycerides were measured on the second or third hospital day. Areas of subcutaneous adipose tissue and visceral adipose tissue were measured on computed tomography (CT). In addition, vascular endothelial function was evaluated under fasting conditions within 4 days of hospitalization, using a PAT device (EndoPAT2000, Itamar Medical).

\section{Biochemical and clinical measurements}

HbA1c levels (\%) were measured using a high-performance liquid chromatography method with a Tosoh HLC-723 G8 analyzer (Tosoh Co., Kyoto, Japan) and expressed in National Glycohemoglobin Standardization Program (NGSP) equivalent values calculated from the following equation: HbA1c $(\mathrm{NGSP})=\mathrm{HbA} 1 \mathrm{c}($ Japan Diabetes Society [JDS]) $(\%)+0.4 \%$ [15]. The homeostasis model assessment of insulin resistance (HOMA-IR) values were calculated using the following formula: FPG $(\mathrm{m} / \mathrm{dL}) \times \mathrm{FPI}$ $(\mu \mathrm{U} / \mathrm{mL}) / 405$. The homeostasis model assessment of $\beta$-cell function (HOMA- $\beta$ ) values were calculated using the following formula: FPI $(\mu \mathrm{U} / \mathrm{mL}) \times 360 /(\mathrm{FPG}[\mathrm{mg} / \mathrm{dL}]-63)$. The CPR index was calculated using the following formula: $\mathrm{CPR}(\mathrm{ng} / \mathrm{mL}) / \mathrm{FPG}(\mathrm{m} / \mathrm{dL}) \times 100$. Total homocysteine levels were measured using high-performance liquid chromatography (SRL Co., Tokyo, Japan). Carotid intima-media thickness (IMT) was measured by a well-trained medical technologist from the Hospital of the University of Occupational and Environmental Health, Japan. The highest IMT value was defined as the maximum IMT. The mean values of the right and left maximum IMT were used for statistical analysis. If a plaque was present, it was included in the IMT measurement. Serum 25(OH)D levels were measured using the DIASource $250 \mathrm{H}$ Vitamin D total-RIA-CT Kit (DIAsource ImmunoAssay Co., Louvain-la-Neuve, Belgium) by radioimmunoassay. A 25(OH)D level $<20 \mathrm{ng} / \mathrm{mL}$ indicated vitamin D deficiency [16].

\section{Noninvasive vascular function test}

We used the PAT-based method for digital assessment of vascular endothelial function as described in detail previously [17]. Briefly, after an acclimatization period of $30 \mathrm{~min}$ (before breakfast) in a temperature- and light-controlled room, the baseline pulse amplitude was recorded during a period of 5 min before the induction of ischemia. Ischemia was induced by placing the sphygmomanometer cuff on the upper arm, while the opposite arm served as the control. The PAT probes were placed on one finger of each hand. After $5 \mathrm{~min}$, the blood pressure cuff was inflated to $60 \mathrm{mmHg}$ above the systolic pressure or to $200 \mathrm{mmHg}$ for $5 \mathrm{~min}$ and then deflated to induce reactive hyperemia. As a measure of reactive hyperemia, the RHI was calculated as the ratio of the average amplitude of the PAT signal over 1 min beginning 1.5 min after cuff deflation (control arm, A; occluded arm, C) divided by the average amplitude of the PAT signal over the 2.5-min period before cuff inflation (baseline) (control arm, B; occluded arm, D). Thus, the following formula was used: $\mathrm{RHI}=(\mathrm{C} / \mathrm{D}) /(\mathrm{A} / \mathrm{B}) \times$ baseline correction. In this study, an $\mathrm{RHI}<1.67$ was used to define vascular endothelial dysfunction $[18,19]$ 


\section{Statistical analysis}

Data are expressed as mean \pm standard deviation. Data distribution was determined using the ShapiroWilk test. Categorical values were tested by the $-\chi 2$ test. Comparison of the characteristics of T2D patients with low and high vitamin D levels was carried out using the paired t-test for normally distributed data and the Wilcoxon signed-rank test for data with skewed distribution. Correlation analyses between serum 25(OH)D levels and the baseline characteristics of patients were performed using Pearson's correlation analysis for normally distributed variables and Spearman's correlation analysis for variables with skewed distribution. To investigate the predictive value of serum $25(\mathrm{OH}) \mathrm{D}$ levels for vascular endothelial dysfunction in patients with T2D, receiver operating characteristic (ROC) curves were plotted to determine the optimal cut-off value of serum 25(OH)D level. In addition, we also performed univariate and multivariate logistic regression analyses. In the multivariate logistic regression analysis, the independent variables were chosen from age, sex, other factors with $p$ values of less than $5 \%$ in the univariate logistic regression analysis, after excluding factors showing multicollinearity on Spearman's correlation analysis. Data were expressed as odds ratios (ORs) and $95 \%$ confidence intervals (Cls). All statistical analyses were carried out using SPSS version 25.0 (SPSS Inc., Chicago, IL). A $p$ value less than 0.05 was considered to denote statistical significance.

\section{Results}

\section{Patient demographics}

The baseline characteristics of the study patients are summarized in Table 1. The mean disease duration was 7.3 years and the mean $\mathrm{HbA1c}$ level was 9.3\%. The mean serum 25(OH)D level was $18.4 \pm$ $8.1 \mathrm{ng} / \mathrm{mL}$. The proportion of patients with vitamin D deficiency was $66.4 \%$ and that of patients with vascular endothelial dysfunction $(\mathrm{RHI}<1.67)$ was $49.6 \%$. 
Table 1

Baseline characteristics of T2D patients.

n

Age (years)

Sex (men/women)

Duration of diabetes (year)

Body mass index $\left(\mathrm{kg} / \mathrm{m}^{2}\right)$

Systolic blood pressure $(\mathrm{mmHg})$

Diastolic blood pressure $(\mathrm{mmHg})$

FPG $(\mathrm{mg} / \mathrm{dL})$

$\mathrm{HbA1c}(\%)$

$\mathrm{FPI}(\mu \mathrm{g} / \mathrm{mL})$

HOMA-IR

HOMA- $\beta$ (\%)

S-CPR $(\mathrm{ng} / \mathrm{mL})$

CPR index

$\operatorname{EGFR}\left(\mathrm{mL} / \mathrm{min} / 1.73 \mathrm{~m}^{2}\right)$

UACR ( $\mathrm{mg} / \mathrm{g}$ Cre)

LDL-C (mg/dL)

$\mathrm{HDL}-\mathrm{C}(\mathrm{mg} / \mathrm{dL})$

TG (mg/dL)

Calcium $(\mathrm{mg} / \mathrm{dL})$

Phosphate (mg/dL)

25(OH)D (ng/mL)
113

$59.8 \pm 12.6$

$64 / 49$

$7.3 \pm 8.0$

$27.5 \pm 6.1$

$132.4 \pm 15.6$

$78.9 \pm 11.6$

$157.4 \pm 43.0$

$9.3 \pm 1.9$

$9.2 \pm 6.1$

$3.5 \pm 2.2$

$43.2 \pm 39.9$

$2.5 \pm 1.3$

$1.6 \pm 0.9$

$79.2 \pm 22.6$

$131.5 \pm 396.6$

$109.1 \pm 38.3$

$47.3 \pm 11.9$

$155.0 \pm 87.6$

$9.5 \pm 0.4$

$3.6 \pm 0.5$

$18.4 \pm 8.1$

Data are mean \pm standard deviation, or $\mathrm{n}(\%)$.

T2D, type 2 diabetes; FPG, fasting plasma glucose; $\mathrm{HbA} 1 \mathrm{c}$, glycated hemoglobin; $\mathrm{FPI}$, fasting plasma insulin; HOMA-IR, homeostasis model assessment of insulin resistance; HOMA- $\beta$, homeostasis model assessment of $\beta$ cell function; S-CPR, serum $C$ peptide, CPR index, Serum C-peptide index; EGFR, estimated glomerular filtration rate; UACR; urinary albumin-to-creatinine ratio, LDL-C, low-density cholesterol; HDL-C, high-density cholesterol; TG, triglyceride; 25(OH)D, 25-hydroxyvitamin D; Carotid IMT, Carotid intima-media thickness; RHI, reactive hyperemia index; DPP-4, dipeptidyl peptidase-4; SGLT-2, Sodium-glucose cotransporter 2; GLP-1, glucagon-like peptide-1. 
n

Vitamin D deficiency (\%)

Subcutaneous adipose tissue areas $\left(\mathrm{cm}^{2}\right)$

Visceral adipose tissue areas $\left(\mathrm{cm}^{2}\right)$

Carotid IMT (mm)

Carotid plaque (\%)

Total homocysteine $(\mathrm{nmol} / \mathrm{L})$

$\mathrm{RHI}$

RHII1.67 (\%)

Hypertension (\%)

Dyslipidemia (\%)

Antihypertensive drug (\%)

Antilipidemic drug (\%)

Diabetes therapy

No medication (\%)

DPP-4 inhibitor (\%)

Sulfonylurea (\%)

Glinide (\%)

Biguanide (\%)

Thiazolidine (\%)

a-glucosidase inhibitor (\%)

SGLT-2 inhibitor (\%)

Insulin (\%)

GLP-1 receptor agonist (\%)

Data are mean \pm standard deviation, or $\mathrm{n}(\%)$.

T2D, type 2 diabetes; FPG, fasting plasma glucose; $\mathrm{HbA} 1 \mathrm{c}$, glycated hemoglobin; $\mathrm{FPI}$, fasting plasma insulin; HOMA-IR, homeostasis model assessment of insulin resistance; HOMA- $\beta$, homeostasis model assessment of $\beta$ cell function; S-CPR, serum C peptide, CPR index, Serum C-peptide index; EGFR, estimated glomerular filtration rate; UACR; urinary albumin-to-creatinine ratio, LDL-C, low-density cholesterol; HDL-C, high-density cholesterol; TG, triglyceride; 25(OH)D, 25-hydroxyvitamin D; Carotid IMT, Carotid intima-media thickness; RHI, reactive hyperemia index; DPP-4, dipeptidyl peptidase-4; SGLT-2, Sodium-glucose cotransporter 2; GLP-1, glucagon-like peptide-1.
$46(40.7)$

\section{3}

75 (66.4)

$218.4 \pm 127.6$

$186.4 \pm 75.9$

$1.0 \pm 0.4$

71 (63.4)

$10.7 \pm 4.3$

$1.85 \pm 0.58$

56 (49.6)

81 (71.7)

85 (75.2)

51 (45.1)

40 (35.4)

47 (39.8)

30 (26.5)

2 (1.8)

28 (24.8)

6 (5.3)

5 (4.4)

3 (2.7)

17 (15.0)

$6(0.5)$ 
Diabetic microvascular complications

Retinopathy (\%)

Nephropathy (\%)

Neuropathy (\%)

Diabetic macrovascular complications

Coronary heart disease (\%)

Cerebrovascular disease (\%)

Arteriosclerosis obliterans (\%)

Data are mean \pm standard deviation, or $\mathrm{n}(\%)$.

T2D, type 2 diabetes; FPG, fasting plasma glucose; $\mathrm{HbA} 1 \mathrm{c}$, glycated hemoglobin; FPI, fasting plasma insulin; HOMA-IR, homeostasis model assessment of insulin resistance; HOMA- $\beta$, homeostasis model assessment of $\beta$ cell function; S-CPR, serum $C$ peptide, CPR index, Serum C-peptide index; EGFR, estimated glomerular filtration rate; UACR; urinary albumin-to-creatinine ratio, LDL-C, low-density cholesterol; HDL-C, high-density cholesterol; TG, triglyceride; 25(OH)D, 25-hydroxyvitamin D; Carotid IMT, Carotid intima-media thickness; RHI, reactive hyperemia index; DPP-4, dipeptidyl peptidase-4; SGLT-2, Sodium-glucose cotransporter 2; GLP-1, glucagon-like peptide-1.

\section{Relationship between serum 25(OH)D levels and baseline characteristics}

Table 2 summarizes the correlation coefficients between 25(OH)D levels and the baseline characteristics of T2D patients. There was a significant correlation between serum 25(OH)D level and $\mathrm{RHI}(r=0.285, p=$ 0.002). Serum 25(OH)D levels also correlated significantly with age and HDL-C levels and negatively with $\mathrm{BMI}, \mathrm{HbA} 1 \mathrm{c}, \mathrm{FPI}$, and CPR, UACR, subcutaneous adipose tissue areas, and visceral adipose tissue areas. 
Table 2

Correlation coefficients between 25(OH)D levels and the baseline characteristics of T2D patients

T2D patients

\begin{tabular}{|c|c|c|}
\hline & $r$ & P-value \\
\hline Age & 0.245 & 0.009 \\
\hline Duration of diabetes & 0.049 & 0.610 \\
\hline Body mass index & -0.248 & 0.008 \\
\hline Systolic blood pressure & 0.046 & 0.625 \\
\hline Diastolic blood pressure & 0.077 & 0.419 \\
\hline FPG & 0.014 & 0.883 \\
\hline $\mathrm{HbA1c}$ & -0.193 & 0.041 \\
\hline FPI & -0.315 & 0.002 \\
\hline HOMA-IR & -0.313 & 0.002 \\
\hline HOMA- $\beta$ & -0.243 & 0.017 \\
\hline S-CPR & -0.195 & 0.040 \\
\hline CPR index & -0.133 & 0.162 \\
\hline EGFR & -0.083 & 0.384 \\
\hline UACR & -0.219 & 0.020 \\
\hline LDL-C & -0.056 & 0.560 \\
\hline HDL-C & 0.200 & 0.033 \\
\hline TG & -0.120 & 0.206 \\
\hline Calcium & 0.072 & 0.450 \\
\hline Phosphate & -0.141 & 0.135 \\
\hline Subcutaneous adipose tissue areas & -0.318 & 0.001 \\
\hline Visceral adipose tissue areas & -0.194 & 0.040 \\
\hline Carotid IMT & 0.028 & 0.769 \\
\hline Total homocysteine & -0.128 & 0.184 \\
\hline $\mathrm{RHI}$ & 0.285 & 0.002 \\
\hline
\end{tabular}




\section{Characteristics of patients with low vitamin D levels}

The ROC curve analysis identified $16.5 \mathrm{ng} / \mathrm{mL}$ as the optimal cut-off level of serum 25(OH)D for the prediction of $\mathrm{RHI}<1.67$ in T2D patients, with sensitivity and specificity of $68.5 \%$ and $67.9 \%$, respectively, and an area under the ROC curve (AUC) of 0.668 (95\% Cl: $0.566-0.770)$. Based on this cut-off value, the patients were divided into those with low vitamin $D$ levels $(25(\mathrm{OH}) \mathrm{D}<16.5 \mathrm{ng} / \mathrm{mL})$ and those with high vitamin D levels $(25(\mathrm{OH}) \mathrm{D} \geq 16.5 \mathrm{ng} / \mathrm{mL}$ ), and their characteristics were compared (Table 3$)$. The mean serum $25(\mathrm{OH}) \mathrm{D}$ level of the low vitamin $\mathrm{D}$ group was almost $50 \%(12.2 \pm 2.6 \mathrm{ng} / \mathrm{mL})$ of that of the high vitamin $D$ group $(24.6 \pm 6.9 \mathrm{ng} / \mathrm{mL})$. Patients of the low vitamin $D$ group were significantly younger, had lower HDL-C levels, and significantly higher values of BMI, FPI, CPR, subcutaneous adipose tissue areas, visceral adipose tissue areas, and total homocysteine than those of the high vitamin $\mathrm{D}$ group. The low vitamin $D$ group also showed significantly lower $R H I$ values than the high vitamin $D$ group $(1.70 \pm 0.54$ vs. $1.98 \pm 0.58 ; p<0.001$, Fig. 1). The proportion of patients with $R H I<1.67$ was also higher in the low vitamin $D$ group than in the high vitamin $D$ group ( $38 \%$ vs. $18 \%$; $p<0.001)$. 
Table 3

Results of comparison between T2D patients with low and high vitamin D levels.

\begin{tabular}{|c|c|c|c|}
\hline & High 25(OH)D & Low 25(OH)D & $\mathbf{P}$ \\
\hline $\mathrm{N}$ & 57 & 56 & \\
\hline Age (years) & $62.3 \pm 11.5$ & $57.4 \pm 13.2$ & 0.038 \\
\hline Sex (men/women) & $36 / 21$ & $28 / 28$ & 0.158 \\
\hline Duration of diabetes (year) & $7.8 \pm 8.6$ & $7.2 \pm 7.3$ & 0.936 \\
\hline Body mass index $\left(\mathrm{kg} / \mathrm{m}^{2}\right)$ & $26.2 \pm 5.6$ & $28.7 \pm 6.4$ & 0.018 \\
\hline Systolic blood pressure $(\mathrm{mmHg})$ & $132.9 \pm 14.8$ & $132.0 \pm 16.6$ & 0.425 \\
\hline Diastolic blood pressure $(\mathrm{mmHg})$ & $79.6 \pm 10.2$ & $78.0 \pm 12.9$ & 0.337 \\
\hline $\mathrm{FPG}(\mathrm{mg} / \mathrm{dL})$ & $156.6 \pm 44.2$ & $157.4 \pm 43.0$ & 0.947 \\
\hline $\mathrm{HbA1c}(\%)$ & $9.0 \pm 1.9$ & $9.5 \pm 1.8$ & 0.114 \\
\hline $\mathrm{FPI}(\mu \mathrm{g} / \mathrm{mL})$ & $7.3 \pm 4.5$ & $11.1 \pm 6.9$ & 0.002 \\
\hline HOMA-IR & $2.8 \pm 1.7$ & $4.2 \pm 2.4$ & 0.001 \\
\hline HOMA- $\beta$ (\%) & $35.9 \pm 34.8$ & $50.5 \pm 43.6$ & 0.028 \\
\hline S-CPR (ng/mL) & $2.2 \pm 1.2$ & $2.7 \pm 1.3$ & 0.016 \\
\hline CPR index & $1.5 \pm 0.9$ & $1.8 \pm 0.9$ & 0.097 \\
\hline $\operatorname{EGFR}\left(\mathrm{mL} / \mathrm{min} / 1.73 \mathrm{~m}^{2}\right)$ & $78.8 \pm 23.6$ & $73.8 \pm 27.7$ & 0.518 \\
\hline UACR (mg/g Cre) & $50.7 \pm 152.1$ & $213.7 \pm 532.1$ & 0.080 \\
\hline LDL-C (mg/dL) & $121.2 \pm 39.9$ & $119.3 \pm 39.1$ & 0.798 \\
\hline $\mathrm{HDL}-\mathrm{C}(\mathrm{mg} / \mathrm{dL})$ & $50.5 \pm 12.3$ & $44.0 \pm 9.8$ & 0.008 \\
\hline $\mathrm{TG}(\mathrm{mg} / \mathrm{dL})$ & $145.8 \pm 84.2$ & $164.4 \pm 90.8$ & 0.129 \\
\hline Calcium (mg/dL) & $9.7 \pm 0.4$ & $9.7 \pm 0.3$ & 0.159 \\
\hline Phosphate (mg/dL) & $3.5 \pm 0.5$ & $3.6 \pm 0.5$ & 0.090 \\
\hline $25(\mathrm{OH}) \mathrm{D}(\mathrm{ng} / \mathrm{mL})$ & $24.6 \pm 6.9$ & $12.2 \pm 2.6$ & $<0.001$ \\
\hline Subcutaneous adipose tissue areas $\left(\mathrm{cm}^{2}\right)$ & $193.7 \pm 120.5$ & $243.5 \pm 130.7$ & 0.017 \\
\hline
\end{tabular}

Data are mean \pm standard deviation, or $\mathrm{n}(\%)$.

$P$ values by the paired t-test for normally distributed data and Wilcoxon signed-rank test for data with skewed distribution. Categorical values were tested by $-\chi 2$ test. $P$ values are for differences between the two groups. Abbreviations as in Table 1. 


\begin{tabular}{|c|c|c|c|}
\hline & High 25(OH)D & Low 25(OH)D & $\mathbf{P}$ \\
\hline Visceral adipose tissue areas $\left(\mathrm{cm}^{2}\right)$ & $171.2 .9 \pm 72.8$ & $201.8 \pm 76.6$ & 0.016 \\
\hline Carotid IMT (mm) & $1.0 \pm 0.5$ & $1.0 \pm 0.4$ & 0.850 \\
\hline Carotid plaque (\%) & $31(55.4)$ & $40(71.4)$ & 0.078 \\
\hline Total homocysteine (nmol/L) & $9.8 \pm 3.3$ & $11.5 \pm 5.1$ & 0.040 \\
\hline $\mathrm{RHI}$ & $1.99 \pm 0.58$ & $1.70 \pm 0.54$ & $<0.001$ \\
\hline $\mathrm{RHI}<1.67(\%)$ & $18(31.6)$ & $38(67.9)$ & $<0.001$ \\
\hline Hypertension (\%) & $38(66.7)$ & $43(76.8)$ & 0.233 \\
\hline Dyslipidemia (\%) & $43(75.4)$ & $42(75.0)$ & 0.957 \\
\hline Antihypertensive drug (\%) & $19(33.3)$ & $32(57.1)$ & 0.011 \\
\hline Antilipidemic drug (\%) & $20(35.7)$ & $20(35.1)$ & 0.944 \\
\hline \multicolumn{4}{|l|}{ Diabetes therapy } \\
\hline No medication (\%) & $27(47.4)$ & $19(33.9)$ & 0.146 \\
\hline DPP-4 inhibitor (\%) & $18(31.6)$ & $25(44.6)$ & 0.153 \\
\hline Sulfonylurea (\%) & $14(24.6)$ & $16(28.6)$ & 0.629 \\
\hline Glinide (\%) & $2(3.5)$ & $0(0.0)$ & 0.252 \\
\hline Biguanide (\%) & $14(24.6)$ & $14(25.0)$ & 0.957 \\
\hline Thiazolidine (\%) & $4(7.0)$ & $2(3.6)$ & 0.348 \\
\hline a-glucosidase inhibitor (\%) & $1(1.8)$ & $4(7.1)$ & 0.176 \\
\hline SGLT-2 inhibitor (\%) & $0(0.0)$ & $3(4.9)$ & 0.118 \\
\hline Insulin (\%) & $8(14.0)$ & $9(16.1)$ & 0.762 \\
\hline GLP-1 receptor agonist (\%) & $3(5.3)$ & $3(5.4)$ & 0.982 \\
\hline \multicolumn{4}{|l|}{ Diabetic microvascular complications } \\
\hline Retinopathy (\%) & $18(31.6)$ & $23(41.1)$ & 0.294 \\
\hline Nephropathy (\%) & $15(26.3)$ & $20(35.7)$ & 0.280 \\
\hline
\end{tabular}

Data are mean \pm standard deviation, or $\mathrm{n}(\%)$.

$P$ values by the paired t-test for normally distributed data and Wilcoxon signed-rank test for data with skewed distribution. Categorical values were tested by $-\chi 2$ test. $P$ values are for differences between the two groups. Abbreviations as in Table 1. 


\begin{tabular}{|c|c|c|c|}
\hline & High 25(OH)D & Low 25(OH)D & $\mathbf{P}$ \\
\hline Neuropathy (\%) & $23(40.4)$ & $20(35.7)$ & 0.612 \\
\hline \multicolumn{4}{|c|}{ Diabetic macrovascular complications } \\
\hline Coronary heart disease (\%) & $4(7.0)$ & $7(12.5)$ & 0.326 \\
\hline Cerebrovascular disease (\%) & $2(3.5)$ & $4(7.1)$ & 0.331 \\
\hline Arteriosclerosis obliterans (\%) & $0(0.0)$ & $0(0.0)$ & - \\
\hline \multicolumn{4}{|c|}{ Data are mean \pm standard deviation, or $\mathrm{n}(\%)$. } \\
\hline
\end{tabular}

\section{Association between serum 25(OH)D levels and vascular endothelial dysfunction}

Finally, we investigated the association between vitamin D levels and vascular endothelial dysfunction. Univariate logistic regression analysis showed a close association between serum 25(OH)D levels and vascular endothelial dysfunction $(\mathrm{RHI}<1.67)$, with an OR of $0.945(95 \% \mathrm{Cl}: 0.899-0.993, \mathrm{p}=0.025)$. However, multivariate logistic regression analysis that included age, sex, and other significant factors selected by univariate analysis based on $p<0.05$, identified carotid IMT and no use of diabetic medications, but not serum 25(OH)D levels were significantly associated with $\mathrm{RHI}<1.67$. When "serum $25(\mathrm{OH}) \mathrm{D}$ levels $<16.5 \mathrm{ng} / \mathrm{mL}$ " was used instead of general serum 25(OH)D levels, it was associated with increased odds of $\mathrm{RHI}<1.67$, even after adjustment for various confounding factors (OR $4.598,95 \% \mathrm{Cl}$ 1.961-10.783, $p<0.001$, Table 4). 
Table 4

Binary logistic regression analyses of variables contributing to vascular dysfunction in type 2 diabetes patients

\begin{tabular}{|c|c|c|c|c|c|c|}
\hline & \multicolumn{3}{|c|}{$\begin{array}{l}\text { Univariate logistic regression } \\
\text { analysis }\end{array}$} & \multicolumn{3}{|c|}{$\begin{array}{l}\text { Multiple logistic regression } \\
\text { analysis }\end{array}$} \\
\hline & $\begin{array}{l}\text { Wald } \\
X^{2}\end{array}$ & $P$ & OR $(95 \% \mathrm{Cl})$ & $\begin{array}{l}\text { Wald } \\
X^{2}\end{array}$ & $P$ & OR (95\% Cl) \\
\hline \multicolumn{7}{|l|}{ Intercept } \\
\hline Age & 0.058 & 0.809 & $\begin{array}{l}0.996(0.967- \\
1.026)\end{array}$ & & & \\
\hline Women & 0.012 & 0.914 & $\begin{array}{l}0.960(0.456- \\
2.021)\end{array}$ & & & \\
\hline $25(\mathrm{OH}) \mathrm{D}$ & 4.207 & 0.025 & $\begin{array}{l}0.945(0.899- \\
0.993)\end{array}$ & & & \\
\hline Dyslipidemia & 4.359 & 0.037 & $\begin{array}{l}2.611(1.001- \\
6.429)\end{array}$ & & & \\
\hline Carotid IMT & 4.564 & 0.033 & $\begin{array}{l}2.747(1.087- \\
6.941)\end{array}$ & 4.074 & 0.044 & $\begin{array}{l}2.712 \\
(1.029- \\
7.147)\end{array}$ \\
\hline $\begin{array}{l}\text { No use of diabetic } \\
\text { medication }\end{array}$ & 8.629 & 0.003 & $\begin{array}{l}0.307(0.139- \\
0.675)\end{array}$ & 0.298 & 2.712 & $\begin{array}{l}0.133 \\
(0.133- \\
0.670)\end{array}$ \\
\hline $25(\mathrm{OH}) \mathrm{D}<16.5^{\dagger}$ & 14.176 & $<001$ & $\begin{array}{l}4.574(2.073- \\
10.093)\end{array}$ & 12.307 & $<0.001$ & $\begin{array}{l}4.598 \\
(1.961- \\
10.783)\end{array}$ \\
\hline \multicolumn{7}{|c|}{$\begin{array}{l}\text { Age, sex, and factors with } \mathrm{P}<0.05 \text { on univariate logistic regression were included in this multiple } \\
\text { logistic regression. }\end{array}$} \\
\hline
\end{tabular}

\section{Discussion}

The main finding of the present study is the presence of a significant correlation between serum 25(OH)D levels and RHI in T2D patients; in particular, low levels of serum 25(OH)D (less than $16.5 \mathrm{ng} / \mathrm{mL}$ ) were associated with more than 4 -fold increase in the risk of vascular endothelial dysfunction. Given the high incidence of cardiovascular events in T2D patients, we advocate evaluation of vascular endothelial function in this population. Compared to FMD measurement, which is conventionally used for the assessment of vascular endothelial function in clinical practice, $\mathrm{RHI}$, which was used in this study, is advantageous in that it is a simple test that does not require high level of skills. Moreover, one of the major conclusions of the Framingham Heart Study was that the EndoPAT-based RHI measurement is a 
useful measure of peripheral vascular function [20]. To this effect, both RHI and FMD are useful measures of vascular endothelial function and can predict cardiovascular events, but they do not correlate with each other and have been shown to be associated with different risk factors [21]. With the exception of one study that examined the beneficial effects of vitamin D supplementation on RHI [22], there is little or no information on the association between vitamin D levels and RHI in T2D patients. Although our study was retrospective in nature, it was the first to demonstrate the association of low 25(OH)D levels and $\mathrm{RHI}$ in T2D patients.

What are the cellular mechanisms behind the effects of vitamin D on vascular endothelial function? While our study did not directly examine these mechanisms, we postulate the following scenarios. First, calcitriol, an active form of vitamin D, enhances angiogenic responses, such as endothelial repair by promoting the differentiation of monocytes into myeloid angiogenic cells. Second, calcitriol augments endothelial function by increasing endothelial nitric oxide (NO) synthase expression [23]. Third, vitamin D can also improve vascular endothelial function through the regulation of vascular smooth muscle cell proliferation and chronic inflammation [24].

In this study, vitamin D deficiency, defined by a $25(\mathrm{OH}) \mathrm{D}$ level $<20 \mathrm{ng} / \mathrm{mL}$, was observed in $66 \%$ of T2D patients. Using the same definition, a previous 5-year observational study of T2D patients identified hypovitaminosis $\mathrm{D}$ to be associated with increased risks of microvasculopathies as well as macrovasculopathies [25]. Moreover, high hazard ratios of severe vitamin D deficiency were identified for all-cause mortality (2.03) and cardiovascular mortality (1.90) in T2D patients [26]. These findings highlight the clinical importance of hypovitaminosis D in T2D patients. It is noteworthy that our study showed that serum vitamin $D$ level had no significant effect on the incidence of microvasculopathies or macrovasculopathies. The discrepancy in this finding between our study and the above previous studies is probably due to the differences in the sample size, racial composition, and study design. In contrast, a significant correlation was observed between $\mathrm{RHI}$ and serum 25(OH)D levels, suggesting that vascular endothelial dysfunction due to vitamin $D$ deficiency can occur in relatively early stages of T2D. The ROC curve analysis used in the present study found that the cut-off level of 25(OH)D for predicting an $\mathrm{RHI}<$ 1.67 was $16.5 \mathrm{ng} / \mathrm{mL}$ (OR 4.598, 95\% Cl 1.961-10.783, $\mathrm{p}<0.001$; Table 4). Moreover, serum 25(OH)D level of $<20 \mathrm{ng} / \mathrm{mL}$ was also identified by the multivariate logistic regression analysis to be an independent predictor of $\mathrm{RHI}<1.67$ (OR 2.574, 95\% $\mathrm{Cl} 1.043-6.355, \mathrm{P}=0.040)$, suggesting that vitamin $\mathrm{D}$ deficiency defined as $25(\mathrm{OH}) \mathrm{D}$ levels $<20 \mathrm{ng} / \mathrm{mL}$ is associated with vascular endothelial dysfunction.

It is important to determine whether vitamin D supplementation can ameliorate vascular endothelial dysfunction in vitamin D deficient T2D patients. Among the limited number of studies using RHI, one study showed that treatment of vitamin D deficiency with 2,000 or 4,000 IU of cholecalciferol for 16 weeks resulted in only a borderline increase in $\mathrm{RHI}(\mathrm{p}=0.07)$ in T2D patients [22]. Inconsistent results have also been obtained using the FMD, with some studies demonstrating improvement [27] and others reported no changes $[28,29]$. In a recent meta-analysis study investigating the effects of supplemental vitamin $D$ on endothelial function, a sub-analysis involving T2D patients with vitamin $D$ supplementation showed no significant improvement in FMD [30]. Meanwhile, in the D2d Study, which evaluated the 
effects of vitamin D supplementation in individuals with prediabetes, although the risk of T2D was not reduced in the entire population, a $62 \%$ reduction in diabetes risk was observed in a subgroup of patients with a $25(\mathrm{OH}) \mathrm{D}$ level $<12 \mathrm{ng} / \mathrm{mL}$ [31]. While that study did not evaluate vascular endothelial function, the results do not rule out the possibility that vitamin $D$ supplementation improves vascular endothelial function in vitamin D-deficient T2D patients, thus warranting further research on this topic.

This study has several limitations. First, it did not include a control group of non-diabetics. However, it has already been documented that serum $25(\mathrm{OH}) \mathrm{D}$ levels are lower in diabetics than in non-diabetics. Moreover, our retrospective study only included inpatients and could not include other non-diabetic inpatients. Other limitations include a small sample size due to the retrospective design and the lack of consideration of seasonal variations in $25(\mathrm{OH}) \mathrm{D}$ measurements. Finally, this study did not consider whether antidiabetic treatment could by itself improved both vascular endothelial function and serum vitamin $D$ levels of diabetic patients, which should be addressed in future studies.

\section{Conclusions}

In conclusion, we have demonstrated in this study a significant correlation between 25(OH)D levels and $\mathrm{RHI}$ in T2D patients; in particular, low serum 25(OH)D levels $(<16.5 \mathrm{ng} / \mathrm{mL})$ were associated with more than 4-fold increase in the risk of vascular endothelial dysfunction. Our data suggest that serum $25(\mathrm{OH}) \mathrm{D}$ is a potentially useful biomarker for vascular endothelial dysfunction in T2D patients.

\section{Abbreviations}

25(OH)D, 25-hydroxyvitamin D, AUC: Area under the receiver operating characteristic curve, BMI: Body mass index, Cl: Confidence intervals, s-CPR: Serum C peptide, CT: Computed tomography, eGFR: estimated glomerular filtration rate, FMD: Flow-mediated dilation, FPI: Fasting plasma insulin, HbA1c: glycated hemoglobin, HOMA-IR: homeostasis model assessment of insulin resistance; HOMA- $\beta$ : homeostasis model assessment of $\beta$ cell function, IMT: Intima-media thickness, JDS: Japan Diabetes Society, NGSP: National Glycohemoglobin Standardization Program, OR: Odds ratios, PAT: Peripheral arterial tonometry, RHI: Reactive hyperemia index, ROC: Receiver operating characteristic, T2D: type 2 diabetes, UACR: urinary albumin-to-creatinine ratio

\section{Declarations}

\section{Ethics approval and consent to participate}

The study protocol was approved by the ethics committee of the University of Occupational and Environmental Health, Japan (Approval No. H27-186). Informed consent was obtained from each participant.

\section{Consent for publication}




\section{Availability of data and materials}

The datasets generated and analyzed in this study are available from the corresponding author upon reasonable request.

\section{Competing interests}

The authors declare no competing interests.

\section{Funding}

None of the authors received specific financial support for this article.

\section{Authors' contributions}

All authors conceived and designed the study. KT performed the statistical analysis. All authors read and approved the final manuscript.

\section{Acknowledgments}

Not applicable.

\section{References}

1. Haffner SM, Lehto S, Rönnemaa T, Pyörälä K, Laakso M. Mortality from coronary heart disease in subjects with type 2 diabetes and in nondiabetic subjects with and without prior myocardial infarction. N Engl J Med. 1998; 339: 229-34.

2. Stamler J, Vaccaro O, Neaton JD, Wentworth D. Diabetes, other risk factors, and 12-yr cardiovascular mortality for men screened in the Multiple Risk Factor Intervention Trial. Diabetes care. 1993; 16: 43444.

3. Kannel WB, McGee DL. Diabetes and cardiovascular disease. The Framingham study. JAMA. 1979; 241: 2035-8.

4. Fonseca V, Desouza C, Asnani S, Jialalet I. Nontraditional risk factors for cardiovascular disease in diabetes. Endocr Rev. 2004; 25: 153-75.

5. Ross R. Atherosclerosis--an inflammatory disease. N Engl J Med. 1999; 340: 115-26. 
6. Xu J, Zou M-H. Molecular insights and therapeutic targets for diabetic endothelial dysfunction. Circulation. 2009; 120: 1266-86.

7. Dobnig H, Pilz S, Scharnagl H, Renner W, Seelhorst U, Wellnitz B, et al. Independent association of low serum 25-hydroxyvitamin $d$ and 1,25-dihydroxyvitamin d levels with all-cause and cardiovascular mortality. Arch Intern Med. 2008; 168: 1340-9.

8. Pilz S, März W, Wellnitz B, Seelhorst U, Fahrleitner-Pammer A, Dimai HP, et al. Association of vitamin $D$ deficiency with heart failure and sudden cardiac death in a large cross-sectional study of patients referred for coronary angiography. J Clin Endocrinol Metab. 2008; 93: 3927-35.

9. Cigolini M, lagulli MP, Miconi V, Galiotto M, Lombardi S, Targher G. Serum 25-hydroxyvitamin D3 concentrations and prevalence of cardiovascular disease among type 2 diabetic patients. Diabetes Care. 2006; 29: 722-4.

10. Hyppönen E, Power C. Vitamin D status and glucose homeostasis in the 1958 British birth cohort: the role of obesity. Diabetes Care. 2006; 29: 2244-6.

11. Yiu YF, Chan YH, Yiu KH, Siu CW, Li SW, Wong LY, et al. Vitamin D deficiency is associated with depletion of circulating endothelial progenitor cells and endothelial dysfunction in patients with type 2 diabetes. J Clin Endocrinol Metab. 2011; 96: E830-5.

12. Rubinshtein R, Kuvin JT, Soffler M, Lennon RJ, Lavi S, Nelson RE, et al. Assessment of endothelial function by non-invasive peripheral arterial tonometry predicts late cardiovascular adverse events. Eur Heart J. 2010; 31: 1142-8.

13. Matsue Y, Yoshida K, Nagahori W, Ohno M, Suzuki M, Matsumura A, et al. Peripheral microvascular dysfunction predicts residual risk in coronary artery disease patients on statin therapy. Atherosclerosis. 2014; 232: 186-90.

14. Haneda M, Utsunomiya K, Koya D, Babazono T, Moriya T, Makino H, et al. A new Classification of Diabetic Nephropathy 2014: A report from Joint Committee on Diabetic Nephropathy. J Diabetes Investig. 2015; 6: 242-6.

15. Seino Y, Nanjo K, Tajima N, Kadowaki T, Kashiwagi A, Araki E, et al. Report of the committee on the classification and diagnostic criteria of diabetes mellitus. J Diabetes Investig. 2010; 1: 212-28.

16. Holick MF. Vitamin D deficiency. N Engl J Med. 2007; 357: 266-81.

17. Bonetti PO, Pumper GM, Higano ST, Holmes DR Jr, Kuvin JT, Lerman A. Noninvasive identification of patients with early coronary atherosclerosis by assessment of digital reactive hyperemia. J Am Coll Cardiol. 2004; 44: 2137-41.

18. Syvänen K, Korhonen P, Partanen A, Aarnio P. Endothelial function in a cardiovascular risk population with borderline ankle-brachial index. Vasc Health Risk Manag. 2011; 7: 97-101.

19. Igari K, Kudo T, Toyofuku T, Inoue Y. The Relationship between Endothelial Dysfunction and Endothelial Cell Markers in Peripheral Arterial Disease. PLoS one. 2016; 11: e0166840.

20. Hamburg NM, Keyes MJ, Larson MG, Vasan RS, Schnabel R, Pryde MM, et al. Cross-sectional relations of digital vascular function to cardiovascular risk factors in the Framingham Heart Study. Circulation. 2008; 117: 2467-74. 
21. Hamburg NM, Palmisano J, Larson MG, Sullivan LM, Lehman BT, Vasan RS, et al. Relation of brachial and digital measures of vascular function in the community: the Framingham heart study. Hypertension. 2011; 57: 390-6.

22. Dalan R, Liew H, Assam PN, Chan ES, Siddiqui FJ, Tan AW, et al. A randomised controlled trial evaluating the impact of targeted vitamin D supplementation on endothelial function in type 2 diabetes mellitus: The DIMENSION trial. Diab Vasc Dis Res. 2016; 13: 192-200.

23. Reynolds JA, Haque S, Williamson K, Ray DW, Alexander MY, Bruce IN. Vitamin D improves endothelial dysfunction and restores myeloid angiogenic cell function via reduced CXCL-10 expression in systemic lupus erythematosus. Sci Rep. 2016; 6: 22341.

24. Mangge $H$, Weghuber D, Prass I R, Haara A, Schnedl W, Postolache TT, et al. The role of vitamin D in atherosclerosis inflammation revisited: More a bystander than a player? Curr Vasc Pharmacol. 2015; 13: 392-8.

25. Herrmann M, Sullivan DR, Veillard AS, McCorquodale T, Straub IR, Scott R, et al. Serum 25hydroxyvitamin D: A predictor of macrovascular and microvascular complications in patients with type 2 diabetes. Diabetes care. 2015; 38: 521-8.

26. Joergensen C, Gall MA, Schmedes A, Tarnow L, Parving HH, Rossing P. Vitamin D levels and mortality in type 2 diabetes. Diabetes care. 2010; 33: 2238-43.

27. Sugden JA, Davies JI, Witham MD, Morris AD, Struthers AD. Vitamin D improves endothelial function in patients with type 2 diabetes mellitus and low vitamin D levels. Diabet Med. 2008; 25: 320-5.

28. Yiu YF, Yiu KH, Siu CW, Chan YH, Li SW, Wong LY, et al. Randomized controlled trial of vitamin D supplement on endothelial function in patients with type 2 diabetes. Atherosclerosis. 2013; 227: 1406.

29. Barchetta I, Del Ben M, Angelico F, Di Martino M, Fraioli A, La Torre G, et al. No effects of oral vitamin D supplementation on non-alcoholic fatty liver disease in patients with type 2 diabetes: a randomized, double-blind, placebo-controlled trial. BMC Med. 2016; 14: 92.

30. Pincombe NL, Pearson MJ, Smart NA, King N, Dieberg G. Effect of vitamin D supplementation on endothelial function - An updated systematic review with meta-analysis and meta-regression. Nutrition, metabolism, and cardiovascular diseases: Nutr Metab Cardiovasc Dis. 2019; 29: 1261-72.

31. LeBlanc ES, Pratley RE, Dawson-Hughes B, Staten MA, Sheehan PR, Lewis MR, et al. Baseline characteristics of the vitamin D and type 2 diabetes (D2d) study: A contemporary prediabetes cohort that will inform diabetes prevention efforts. Diabetes Care. 2018; 41: 1590-9.

\section{Figures}




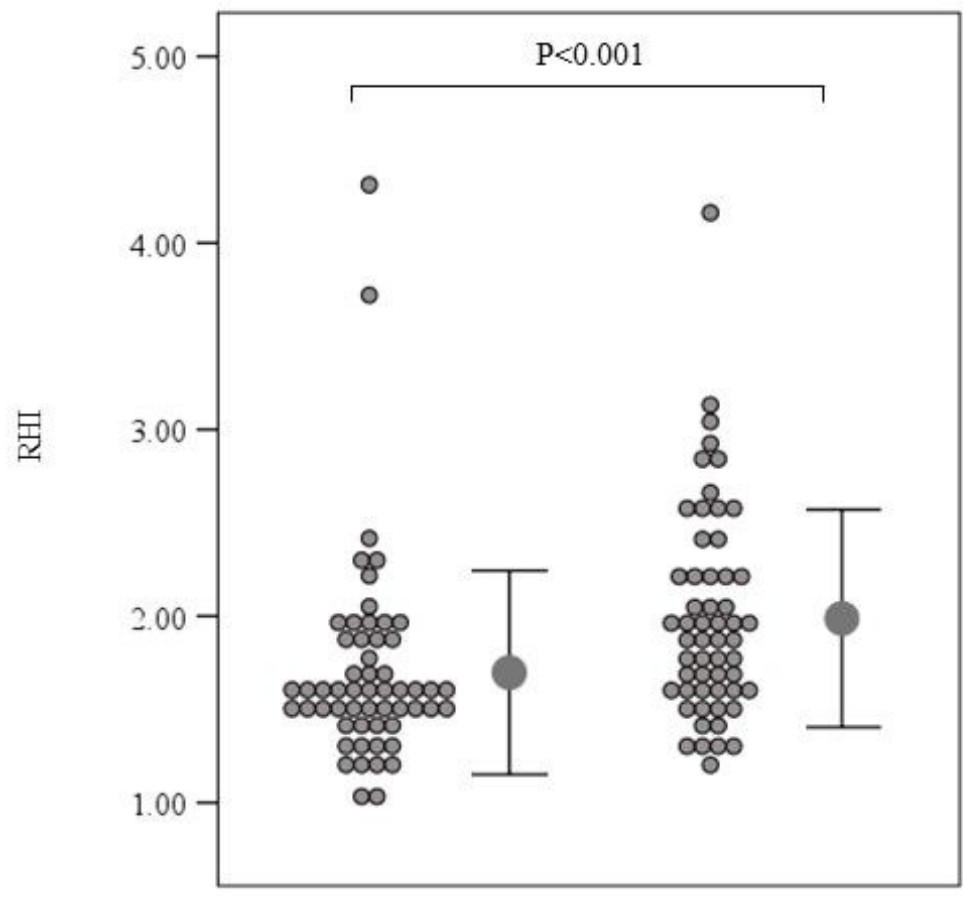

Low $25(\mathrm{OH}) \mathrm{D}$

High 25(OH)D

$(<16.5 \mathrm{ng} / \mathrm{mL})$

$(\geq 16.5 \mathrm{ng} / \mathrm{mL})$

\section{Figure 1}

Comparison of RHI between T2D patients with low and high vitamin D levels. Symbols represent individual data and circles with lines are group mean \pm SD values. $25(\mathrm{OH}) \mathrm{D} ; 25$-hydroxyvitamin $\mathrm{D}, \mathrm{RHI}$; Reactive hyperemia index 